\title{
OS CAMPOS CONCEITUAIS DE VERGNAUD COMO FERRAMENTA PARA O PLANEJAMENTO DIDÁTI- $\mathrm{CO}^{+*}$
}

Gabriel Dias de Carvalho Jr.

Colégio Marista Dom Silvério/Colégio Santa Dorotéia/Unimaster

Orlando Aguiar Jr.

Faculdade de Educação - UFMG

Belo Horizonte - MG

\section{Resumo}

Este trabalho tem como objetivo apresentar a teoria dos campos conceituais de Vergnaud (1990) como instrumento para o planejamento e para a análise das atividades de intervenção didática. A pesquisa foi realizada com estudantes da segunda série do Ensino Médio, durante o estudo da Física Térmica. Ele faz parte da dissertação de mestrado defendida por um dos autores (CARVALHO $J R ., 2005)$, na qual acompanhamos as trajetórias de aprendizagem de sete estudantes. Os resultados desse estudo foram analisados utilizando-se ferramentas provenientes da Teoria de Campos Conceituais. Neste trabalho, a ênfase será dada à análise e justificativa das categorias propostas por Vergnaud, tal como apropriadas por nós no desenho da pesquisa.

Palavras-chave: Campos Conceituai; planejamento do ensino; desenvolvimento cognitivo.

\footnotetext{
Vergnaud's Theory of Conceptual Fields as a tool for the didactic planning

* Recebido: dezembro de 2005.

Aceito: dezembro de 2007.
} 


\begin{abstract}
The aim of this work is to present Vergnaud's Theory of Conceptual Fields (1990) as a tool for the design and analysis of Science teaching sequences. The classroom study was conducted in a Brazilian High School working with Thermal Physics. It was part of a Master Degree Thesis presented by one of the authors (CARVALHO JR., 2005), in which we followed up the learning pathways of 7 students. The results of this study were analyzed using the Theory of Conceptual Fields. We shall emphasize the main concepts and categories of Vergnaud's Theory and the appropriation we have done about them in this particular research.
\end{abstract}

Keywords: Conceptual Fields; teaching planning; cognitive development.

\title{
I. Introdução
}

Este trabalho apresenta uma das conclusões da pesquisa de mestrado de um dos autores. Nela, acompanhamos as trajetórias de aprendizagem de sete alunos da segunda série do Ensino Médio, com o objetivo de investigar a efetividade de diversificação de estratégias e atividades de ensino, assim como a importância da aquisição do modelo cinético-molecular por parte dos estudantes para uma compreensão mais global dos conceitos básicos da Física Térmica.

Para a realização da pesquisa, construímos uma seqüência de ensino calcada na diversificação de estratégias, como, por exemplo, discussões em grupo, atividades experimentais, atividades mediadas pelo computador e leituras individuais. Tal seqüência foi apresentada no XV Simpósio Nacional de Ensino de Física (CARVALHO, JR. e AGUIAR, JR., 2003). Com a aplicação dessa seqüência de ensino, foi possível acompanhar a evolução dos modelos explicativos dos estudantes sobre os conceitos da Física Térmica.

A seqüência de ensino foi desenvolvida em 24 aulas, entre 28/08/2003 e $20 / 10 / 2003$. O tempo destinado à coleta de dados se estendeu por esse tempo devido às características do trabalho proposto, cuja questão central era a verificação de como evoluem os modelos explicativos dos sujeitos ao longo da seqüência de ensino e em que medida as escolhas realizadas potencializaram a aprendizagem 
dos estudantes. O referencial teórico adotado foi a Teoria dos Campos Conceituais de VERGNAUD (1990; 1993). Partindo do pressuposto de que o tempo de aprendizagem nem sempre coincide com o tempo do ensino, a pesquisa envolveu um período prolongado para que fosse possível acompanhar a evolução dos modelos conceituais dos estudantes, o que envolve período de construção, testagem e sedimentação de idéias.

Queríamos, com a aplicação da seqüência de ensino, permitir que os estudantes revelassem seus modelos explicativos sobre os conceitos da Física Térmica e indicassem as atividades que mais contribuíram para o seu aprendizado ${ }^{1}$. Para tanto, houve momentos previstos de (1) leituras individuais de textos, (2) atividades práticas realizadas em grupo, (3) discussão em pequenos grupos, (4) discussões com toda a turma, ao início ou ao final das atividades e (5) apresentação de animações em computadores. Ao final das atividades indicadas na seqüência de ensino, era solicitada aos grupos de alunos a entrega de uma síntese pessoal sobre o que foi realizado na aula. Tal prática se destinava a recolher material para análise das formas de compreensão acerca dos conceitos estudados e propiciar uma atividade de metacognição, uma vez que, para se elaborar uma síntese das atividades, era solicitado que os estudantes pensassem na influência de cada uma delas em seu processo pessoal de aprendizagem.

Os diversos momentos em que os estudantes estiveram trabalhando com a seqüência de ensino permitiram-nos compor um quadro com as suas trajetórias de aprendizagem. Necessitávamos da demarcação de alguns pontos de verificação que pudessem nos indicar os modelos explicativos utilizados pelos estudantes e, com isso, tentar recuperar as rotas de construção de significados que cada um seguiu.

Como as trajetórias de aprendizagem são pessoais, optamos por não utilizar, como indicadores de progresso, as produções coletivas dos grupos, apesar de creditarmos um grande valor pedagógico aos momentos de interação. Queríamos identificar os modelos explicativos pessoais dos estudantes, construídos em função das atividades desenvolvidas ao longo da seqüência de ensino. Por isso, fizemos a opção de utilizar como indicadores apenas os momentos de produção individual dos estudantes. Assim, tivemos um total de quatro momentos para caracterização

\footnotetext{
${ }^{1}$ Essa indicação era solicitada, informalmente, ao final das atividades. Houve um momento para que os alunos efetuassem uma avaliação, por escrito, do processo. Essa solicitação cumpria dois objetivos: o primeiro era avaliar o próprio instrumento, procurando evidenciar as atividades que melhor cumpriram seus objetivos didáticos; o segundo era buscar evidências das preferências individuais dos sujeitos, elementos constitutivos dos estilos de aprendizagem.
} 
das trajetórias de aprendizagem:

(1) Pré-Teste: aplicado no primeiro dia da pesquisa, antes que qualquer conceito acerca da Física Térmica fosse trabalhado formalmente. Tínhamos dois objetivos ao fazermos o pré-teste: (a) levantar os modelos explicativos dos estudantes e (b) iniciar uma discussão acerca dos conceitos da Física Térmica.

(2) Teste 1: apresentado aos alunos ao final da primeira sessão da seqüência de ensino. Até esse ponto da pesquisa, os estudantes trabalharam com a distinção entre os conceitos de calor e temperatura e com o conceito de equilíbrio térmico.

(3) Teste 2: aplicado ao final do estudo da seqüência de ensino. Os conceitos relacionados à Física Térmica foram estudados tendo como base o modelo cinético-molecular.

(4) Entrevista: conduzida sete meses após o término da seqüência de ensino. Esperamos um grande intervalo de tempo para que pudéssemos verificar a extensão das mudanças nos perfis conceituais dos estudantes, indicados nos testes.

\section{A teoria dos campos conceituais}

Gèrard Vergnaud é um psicólogo pertencente à tradição piagetiana, que procura investigar o sujeito do conhecimento em resposta a uma situação de ensino. $\mathrm{O}$ autor procura redirecionar o foco piagetiano do sujeito epistêmico para o do sujeito-em-situação. Esse deslocamento de objeto central de análise procura responder à pergunta central de como o sujeito aprende em situação ${ }^{2}$.

Os projetos de investigação de Piaget e Vergnaud são complementares quando pensamos em atividades de intervenção didática em sala de aula. Com a análise do sujeito de situação, proposta por Vergnaud, podemos pesquisar e compreender melhor a evolução temporal dos sujeitos à medida que aprendem, bem como pensar em planejamentos de intervenções didáticas centradas nas caracterís-

\footnotetext{
${ }^{2}$ Não se trata de negar a atenção que Piaget deu às situações de pesquisa em suas investigações. Para o desenvolvimento da psicologia genética, era importante que fosse estudado o sujeito em ação. No entanto, parece-nos que esse tipo de investigação foi um passo para que Piaget pudesse compreender o sujeito epistêmico, ou seja, para que fosse possível desenvolver a sua Epistemologia Genética. O interesse do autor em modelos mais gerais e descontextualizados acabou por ocultar o caráter necessariamente situado das ações humanas e as conseqüências disso para a análise do problema do desenvolvimento conceitual.
} 
ticas dos conteúdos que serão estudados. Para o autor, o desenvolvimento cognitivo é fortemente influenciado pelo conteúdo do ensino. A sua teoria dos campos conceituais afirma que o ponto fundamental da cognição é o processo de conceitualização do real, atividade psicológica interna ao sujeito que não pode ser reduzida nem a operações lógicas gerais, tampouco às operações puramente lingüísticas. Para Vergnaud, o desenvolvimento cognitivo não pode ser explicado por modelos simplistas, seja recorrendo a idéias de reprodução social, seja pela emergência de estruturas inatas do sujeito, ou ainda por meio da metáfora da mente como processamento de informação (VERGNAUD, 1998, p. 173).

Por outro lado, com Piaget possuímos dispositivos de análise dos mecanismos gerais do desenvolvimento do sujeito que podem conduzir às aprendizagens. A Teoria da Equilibração (PIAGET, 1986) - com seus conceitos de assimilação, acomodação, perturbação, compensação e equilibração majorante - nos fornece amplas bases para explicar a emergência das novidades no curso das ações e operações de um sujeito frente a um objeto de conhecimento. Essa dimensão funcional da teoria piagetiana é, em essência, preservada na teoria de campos conceituais de Vergnaud, que toma como base o conceito piagetiano de esquema.

Para Vergnaud, o conhecimento está organizado em campos conceituais, cujo domínio por parte do aprendiz vai acontecendo ao longo de um extenso período de tempo, por meio da experiência, maturidade e aprendizagem (MOREIRA, 2002). Esses campos conceituais são recortes do mundo físico com um forte componente cultural associado. Vergnaud define como campo conceitual:

um conjunto informal e heterogêneo de problemas, situações, conceitos, relações, estruturas, conteúdos e operações de pensamento, conectados uns aos outros e, provavelmente, entrelaçados durante o processo de aquisição (VERGNAUD, 1998).

Um ganho em se trabalhar com a Teoria dos Campos Conceituais no planejamento e na análise de situações de ensino é que essa é uma teoria que lida com o desenvolvimento cognitivo e com a aprendizagem a partir dos próprios conteúdos do conhecimento e a análise conceitual do seu domínio (MOREIRA, 2002). Para o autor, o objeto de ensino influencia fortemente a forma como o conhecimento é construído por parte do estudante.

\section{II.1 Justificativas para a Teoria dos Campos Conceituais}

Vergnaud apresenta três justificativas para que se utilize o conceito de campo conceitual como forma de análise para a questão da obtenção de conheci- 
mento:

(1) Um conceito não se forma a partir de um só tipo de situação, o que sugere a necessidade de se diversificarem as atividades de ensino em um movimento que permita ao sujeito a aplicação de um dado conceito em diversas situações e que faça a integração entre as partes e o todo. Vários autores, como HESTENES (1996) e KAPER e GOEDHART (2002) confirmam essa proposição. A necessidade de diversificação de situações cumpre um papel importante na conceitualização, pois fornece uma base para que os estudantes possam testar seus modelos explicativos em contextos diversos, enriquecendo tais modelos ou reformulando-os, como nos indica VOSNIADOU (1994).

(2) Uma situação não se analisa com um só conceito, o que implica na necessidade de uma visão integradora do conhecimento. Atividades didáticas que permitam uma visão generalizante do conhecimento podem contribuir para uma melhor apropriação do mesmo por parte dos estudantes. HESTENES (1996) defende que a redução na quantidade dos conteúdos trabalhados em sala de aula em favor da centralização em conceitos-chave provê a chave para que os estudantes tenham tempo de construir, testar e validar seus modelos explicativos. Acreditamos que, trabalhando os conceitos que estruturam um dado campo conceitual com profundidade e durante um intervalo de tempo suficiente, fornecemos elementos para que os estudantes construam uma visão integradora do que está sendo aprendido.

(3) A construção e apropriação de todas as propriedades de um conceito ou todos os aspectos de uma situação é um processo longo, o que está em perfeita sintonia com o que CLEMENT (2000) afirma acerca da progressão dos modelos pessoais em direção aos modelos científicos. É importante, pois, que os diversos patamares que podem ser atingidos pelos estudantes ao longo de sua instrução sejam levados em conta no desenho e na posterior aplicação de intervenções didáticas. Mesmo que falsos no plano científico, alguns modelos explicativos intermediários podem cumprir um importante papel na trajetória de aprendizagem de um dado sujeito.

$\mathrm{Na}$ teoria dos campos conceituais, o desenvolvimento cognitivo depende fortemente da situação e da conceitualização específicas. O autor entende que a "situação" é uma tarefa, teórica ou empírica, a ser realizada pelo sujeito. Segundo Vergnaud: 
o saber se forma a partir de problemas para resolver, quer dizer,

de situações para dominar. [...] Por 'problema' é preciso entender, no sentido amplo que lhe atribui o psicólogo, toda situação na qual é preciso descobrir relações, desenvolver atividades de exploração, de hipótese e de verificação, para produzir uma solução (1990, p. 52).

Sendo assim, Vergnaud, ao contrário de Piaget, não procura construir uma teoria geral para o desenvolvimento. Ao contrário, procura relacionar o desenvolvimento do sujeito com as tarefas que este é levado a resolver. Nota-se que, para ele, a cognição possui um componente fortemente situado nas situações. O autor afirma que o processo de desenvolvimento cognitivo, por ser fortemente dependente das situações a serem enfrentadas pelo sujeito, tem como cerne a construção de conceitos, ou seja, a conceitualização. A conceitualização é um processo longo, que requer uma diversificação das situações.

\section{II.2 Conceito em Vergnaud}

Se, para Vergnaud, a conceitualização é o cerne do desenvolvimento cognitivo, devemos, pois, compreender o que se entende por conceito na teoria dos campos conceituais. Para o autor, o conceito é tido como formado por três conjuntos:

1. O conjunto das situações (S) que dão sentido ao conceito. A entrada em um campo conceitual se dá pelas situações, que são responsáveis pelo sentido que é atribuído ao conceito, ou seja, um conceito torna-se significativo através de uma variedade de situações. Essa postulação de Vergnaud se inscreve no âmago de sua teoria, uma vez que o foco de análise é o sujeito-em-ação. O conjunto das situações é reconhecido como o referente do conceito. Para a construção da seqüência de ensino que embasou essa pesquisa, iniciamos pela organização das situações que poderiam ser trabalhadas em sala de aula.

2. Os invariantes (I) sobre os quais repousa a operacionalidade dos conceitos. Esses invariantes representam aquilo que se preserva nos conceitos e que permite que sejam reconhecidos como tais nas situações. Os invariantes representam o significado do conceito.

3. As representações simbólicas (R) que podem ser utilizadas para indicar e representar os invariantes e, portanto, representar as situações e procedimentos para lidar com elas. É identificado como o significante do conceito. 
Como exemplo, vamos apresentar os conceitos de calor e temperatura da forma como utilizamos na pesquisa. Na determinação desses conceitos, à luz da Teoria dos Campos Conceituais, teremos que apresentar as situações, os invariantes operatórios e as representações. Para o estabelecimento dos invariantes, optamos, nesse momento, por apresentar um modelo por nós elaborado. É importante perceber que o enunciado de um invariante operatório em um livro didático ou pelo professor, durante uma aula, não significa que o aluno seja capaz de enunciálo e, mesmo se o fizer, poderá fazê-lo de um modo que não corresponda ao conteúdo do conceito evocado pelo livro ou professor (BITTAR, 2002, p. 7).

Tabela 1 - Os conceitos de calor e temperatura, como utilizados no planejamento da seqüência de ensino.

\begin{tabular}{|c|c|c|}
\hline \multicolumn{3}{|l|}{ Conceito: Calor } \\
\hline $\begin{array}{l}\text { Situações que envolvem o } \\
\text { conceito de calor }\end{array}$ & $\begin{array}{l}\text { Invariantes operatórios passí- } \\
\text { veis de serem enunciados } \\
\text { pelos estudantes }\end{array}$ & Representações simbólicas \\
\hline $\begin{array}{l}\text { Processos de aquecimento } \\
\text { e resfriamento. } \\
\text { Sensações térmicas. } \\
\text { Mudanças de estado físi- } \\
\text { co. } \\
\text { Funcionamento de máqui- } \\
\text { nas térmicas. } \\
\text { Interações térmicas entre } \\
\text { sistemas. }\end{array}$ & $\begin{array}{l}\text { O calor sempre flui do objeto } \\
\text { de maior para o de menor } \\
\text { temperatura, sendo, portanto, } \\
\text { um processo assimétrico. } \\
\text { O calor pode provocar varia- } \\
\text { ção de temperatura e/ou } \\
\text { mudança de estado físico. } \\
\text { O calor é um processo irre- } \\
\text { versível. } \\
\text { Há uma equivalência entre } \\
\text { calor e trabalho, como pro- } \\
\text { cessos de transferência de } \\
\text { energia. } \\
\text { Em um sistema isolado ter- } \\
\text { micamente, a quantidade de } \\
\text { calor cedido é igual à quanti- } \\
\text { dade de calor recebido. }\end{array}$ & $\begin{array}{l}\mathrm{Q}=\mathrm{m} . \mathrm{c} . \Delta \mathrm{T}\{\mathrm{Q}=\text { quantidade } \\
\text { de calor; } \mathrm{m}=\text { massa; } \mathrm{c}= \\
\text { calor específico; } \Delta \mathrm{T}=\text { varia- } \\
\text { ção da temperatura }\} \\
\Delta \mathrm{U}=\mathrm{Q}-\mathrm{W}\{\Delta \mathrm{U}=\text { variação } \\
\text { da energia interna de um } \\
\text { sistema; } \mathrm{W}=\text { trabalho reali- } \\
\text { zado }\}\end{array}$ \\
\hline
\end{tabular}




\section{Conceito: Temperatura}

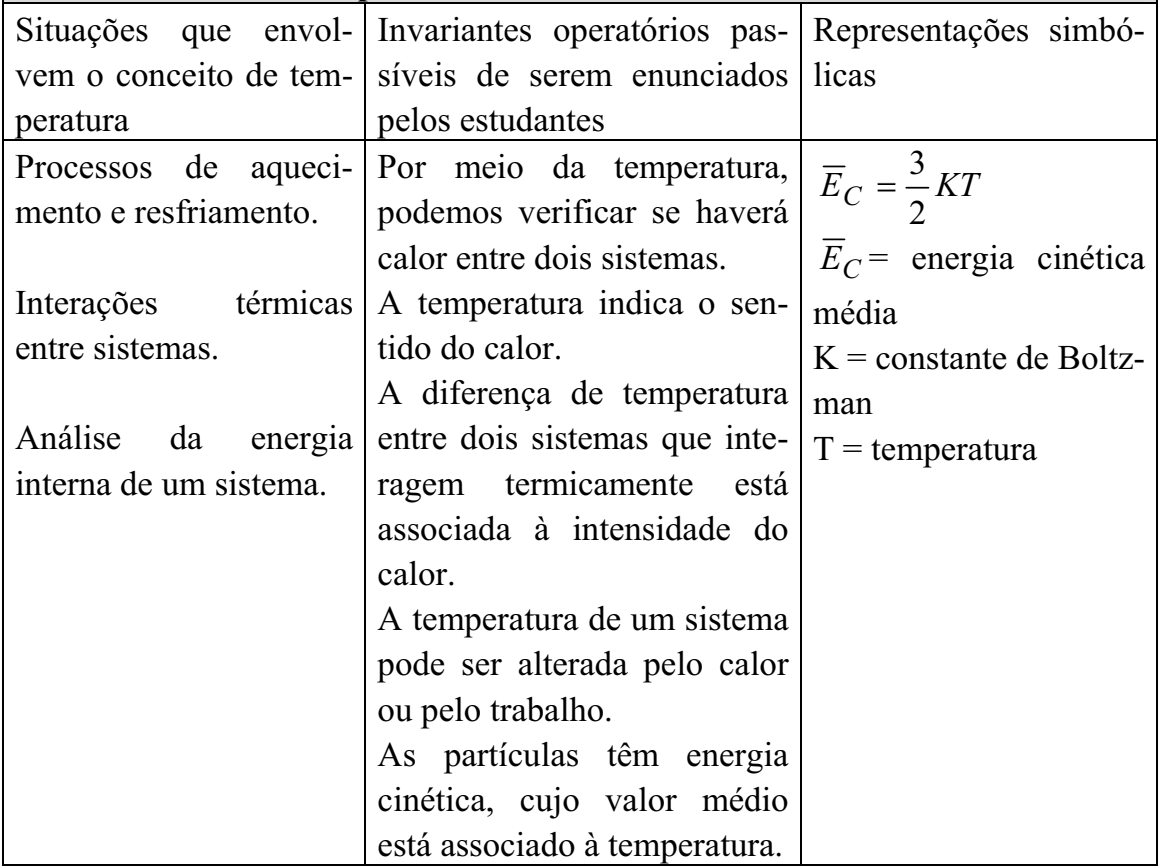

\section{II.3 O esquema}

Frente a uma determinada situação, o sujeito age segundo as representações que dela faz, sendo o esquema o elo entre as representações e a sua conduta. A noção de esquema é, para Vergnaud, a maior contribuição de Piaget e é entendido como "a organização invariante do comportamento para uma determinada classe de situações" (MOREIRA, 2002). Vergnaud afirma que "o conceito de esquema é muito frutífero, não somente para descrever comportamentos familiares, mas também para descrever e compreender os processos de resolução de problemas" (1998, p. 173).

VERGNAUD (1998, p. 173) identifica 4 ingredientes de um esquema, que são:

(1) Metas (objetivos) e antecipações, pois um esquema está orientado sempre à resolução de uma determinada classe de situações.

(2) Regras de ação, busca por informações e controle, que são os elementos que dirigem a seqüência de ações do sujeito;

(3) Invariantes operatórios (teoremas-em-ação e conceitos-em-ação) que 
dirigem o reconhecimento, por parte do indivíduo, dos elementos pertinentes à situação e, portanto, guiam a construção dos modelos mentais;

(4) Possibilidades de inferência (ou raciocínios) que permitem determinar as regras e antecipações a partir das informações e dos invariantes operatórios dos quais dispõe o sujeito.

Desses ingredientes, os invariantes operatórios, cujas categorias principais são teoremas-em-ação e conceitos-em-ação, constituem a base conceitual implícita que permite obter a informação pertinente e, a partir dela e dos objetivos a alcançar, inferir as regras de ação mais pertinentes (VERGNAUD, 1996, p. 201). Assim, é nos esquemas que devemos pesquisar os conhecimentos-em-ação do sujeito (os conceitos-em-ação e as teorias-em-ação), uma vez que é aí que podemos encontrar os elementos que fazem com que a sua ação seja operatória. Vergnaud prefere falar da interação esquema-situação, ao invés da interação sujeito-objeto, como fazia Piaget. O esquema é um referente do sujeito do conhecimento e a situação é a circunstância e o contexto em que o objeto a ele se apresenta.

Em Piaget, de modo semelhante, a interação sujeito-objeto não é direta, mas mediada por esquemas de assimilação que o sujeito dispõe e lança mão ao interagir com o objeto do conhecimento. O que Vergnaud acrescenta a Piaget é uma maior ênfase ao caráter situado da conceitualização. O objeto do conhecimento será, então, sempre um objeto em situação, não existindo uma ordem total linear para as aquisições dos sujeitos.

O conceito de esquema pode conduzir a análise dos conhecimentos-emação do sujeito. Uma das maneiras de se verificar tais conhecimentos é por meio do acompanhamento dos diversos momentos em que os estudantes são chamados a dar respostas a problemas. É possível que se verifique, por meio da análise das estratégias utilizadas na resolução de um problema, os esquemas que um determinado sujeito lança mão, bem como os modelos mentais construídos frente a novas situações. Essa análise permite compor um quadro no qual se observa a evolução temporal dos modelos explicativos dos sujeitos, inferida a partir dos conceitos-emação e dos teoremas-em-ação utilizados ao longo de uma atividade de ensino, de acordo com a teoria dos campos conceituais de Vergnaud.

\section{O planejamento das atividades à luz da teoria dos campos concei- tuais}

A análise dos conteúdos da seqüência de ensino sobre Física Térmica que utilizamos na pesquisa foi feita a partir da teoria dos campos conceituais de 
Vergnaud. Apresentamos e justificamos, a seguir, o modo como nos valemos desta teoria para desenvolvermos e refletirmos sobre as atividades e estratégias do curso.

A partir da análise do conhecimento a ser ensinado, certo aspecto de um campo conceitual é eleito para ser trabalhado em sala-de-aula. No campo da Física térmica, fizemos a escolha da distinção entre calor e temperatura, por entendermos que tal distinção inaugura a possibilidade de um estudo sistemático dos fenômenos térmicos.

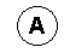

\section{Um aspecto particular de um campo conceitual}

Escolhido o ponto de partida, o professor estabelece as conexões desse aspecto do conteúdo com outros, no âmbito de um campo de conceitos interligados, recorrendo às próprias convicções acerca deste domínio do conhecimento humano e aos objetivos do ensino. As conexões planejadas relacionavam o conceito de energia (cinética e potencial) com os efeitos do calor (variação de temperatura e mudanças de estado físico) e com as leis da Termodinâmica.

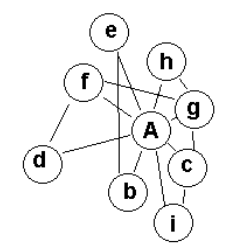

Conexão entre o aspecto escolhido e as demais partes de um campo conceitual

Exploradas as possibilidades de conexões e exploração do campo conceitual, o professor estabelece um recorte no âmbito do campo previamente construído. No caso do planejamento de nossa seqüência de ensino, o recorte que fizemos foi no sentido de trabalhar, inicialmente, com a calorimetria, deixando para uma abordagem posterior o tratamento das leis da Termodinâmica.

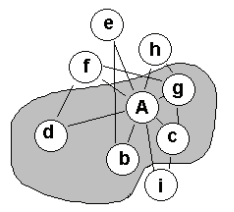

Recorte da parte do campo conceitual que se quer ensinar

Por último, o professor visualiza as situações de ensino e as variáveis didáticas relevantes para a construção de uma seqüência de atividades coerentes e 
inter-relacionadas para o ambiente escolar, de forma cronologicamente organizada em termos de uma seqüência didática.

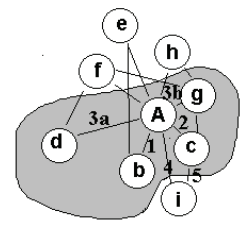

\section{Inter-relações entre os aspectos envolvidos no campo conceitual}

Vamos apresentar, a seguir, a nossa apropriação acerca da Física Térmica em nível elementar. Assim, descreveremos o campo conceitual por nós idealizado para o desenho das situações de ensino. As situações, os conceitos e os teoremas que serão mostrados representam a nossa leitura do que é relevante para um curso introdutório de Física Térmica para o Ensino Médio , considerando circunstâncias de ensino de ciências no Brasil em que raramente tais conteúdos são desenvolvidos adequadamente no Ensino Fundamental.

\section{III.1 Conjunto de situações a compreender e a tratar}

Para Vergnaud, nas situações repousa a operacionalidade dos conceitos e, portanto, são as situações que conferem sentido a um dado conceito. Podemos entender as situações como sendo os problemas que o sujeito deve resolver. A seguir, apresentamos classes de situações por nós identificadas como problemas gerais para o desenvolvimento dos conceitos de calor, temperatura e equilíbrio térmico em nível elementar:

A.1 - os processos de variação de temperatura de um corpo: a indicação de como a temperatura pode variar em um dado sistema;

A. 2 - os processos que envolvem a transferência de calor entre sistemas por condução, convecção, radiação;

A.3 - as sensações de quente e frio: como essas podem ser explicadas considerando-se os conceitos de calor, temperatura e equilíbrio térmico;

A.4 - os fatores que influenciam na variação de temperatura: a influência que a massa e o tipo de material possuem sobre a variação da temperatura de um dado sistema;

A. 5 - os processos de transferência de energia - calor e trabalho - e os efeitos dessa transferência: condições para o estabelecimento do calor e do trabalho e a indicação da equivalência entre esses dois processos na modificação da energia interna de um dado sistema; 
A.6 - a rapidez com que o calor pode ser transferido;

A.7 - a assimetria na transferência de calor: reconhecimento de que o calor só flui do sistema de maior para o de menor temperatura;

A. 8 - situações em que ocorre calor, mas a temperatura do sistema não se altera;

A.9 - a irreversibilidade dos processos: o conceito de entropia como uma grandeza que está associada ao grau de desordem de um sistema que tende a aumentar.

\section{III.2 Os conceitos-em-ação}

Os conceitos-em-ação, tal como propostos por Vergnaud, estão relacionados a objetos, predicados, classes, condições, etc. Dentro de uma vasta quantidade de conceitos que podem estar disponíveis no repertório dos sujeitos, é selecionada uma pequena parte para cada ação. Portanto, os conceitos-em-ação podem ser adequados ou inadeqüados para uma dada classe de situações (VERGNAUD, 1998, p.173). Esses conceitos-em-ação permanecem, em sua maioria, implícitos ao longo da ação do sujeito. Por isso, a análise dos comportamentos e das respostas dadas pelos estudantes foram importantes para inferirmos quais dos conceitos-emação foram utilizados pelos estudantes que estavam sendo acompanhados.

Apresentamos, a seguir, alguns conceitos relacionados à Física Térmica. De acordo com a compreensão dada por Vergnaud para o tema, tais conceitos não podem ser considerados conceitos-em-ação, posto que não são categorias de entendimento de um sujeito em ação frente a uma dada situação. Os conceitos apresentados são, portanto, conceitos científicos preparados para a mediação didática visando sua apropriação por parte de estudantes de um determinado nível de ensino. Poderíamos dizer que se tratam de conceitos científicos escolares relativos à Física térmica para o Ensino Médio . O critério que utilizamos para chegar a eles foi o de selecionar aqueles conceitos que julgamos necessários a um dado sujeito para dar conta das situações listadas no tópico anterior. É importante ressaltar que o conjunto assim construído pode não ser explicitado dessa forma pelos estudantes, tampouco ser reconhecido por eles como conceitos científicos fundamentais.

B.1 - calor: transferência de energia entre dois sistemas motivada, exclusivamente, pela diferença de temperatura entre eles.

B.2 - temperatura: índice associado à energia cinética média das partículas de um sistema. 
B.3 - equilíbrio térmico: tendência final de igualdade de temperaturas decorrente de transferências de energia entre sistemas em contato térmico.

B.4 - capacidade térmica: quantidade de energia necessária para que a temperatura de um determinado sistema varie em uma unidade.

B.5 - condutividade térmica: capacidade de transferência de calor, por condução, de um determinado material ${ }^{3}$.

B.6 - calor latente: quantidade de energia necessária para que uma unidade de massa de um material sofra uma mudança de fase, sem que haja alteração em sua temperatura.

B.7 - entropia: grandeza associada à desorganização dos sistemas.

B. 8 - energia interna: quantidade de energia armazenada em um dado sistema.

\section{III.3 Os teoremas-em-ação}

Os conceitos-em-ação se articulam por meio dos teoremas-em-ação. Os teoremas-em-ação são proposições, que podem ser verdadeiras ou falsas. De maneira análoga àquela apresentada para os conceitos-em-ação, essas proposições permanecem, em sua maioria, implícitas nas ações do sujeito, podendo se tornar explícitas.

Enunciamos, a seguir, algumas relações conceituais que não são teoremas-em-ação, da forma definida por Vergnaud, posto que não se referem a um dado sujeito em ação frente a uma situação-problema. As relações mostradas são aquelas que julgamos importantes para a abordagem e a solução das situações que envolvem a Física Térmica.

C.1 - A temperatura é uma característica de cada sistema, associada à agitação das partículas desse sistema.

C.2 - A temperatura não depende da massa do sistema, pois é proporcional à energia cinética média das partículas.

C. 3 - O calor é a transferência de energia entre sistemas que estão a diferentes temperaturas.

\footnotetext{
${ }^{3}$ Essa definição é pouco precisa e decorre da dificuldade em se definir o conceito de condutividade térmica em linguagem comum. Sem apelar para uma definição matemática, podemos ainda acrescentar que a condutividade térmica é dada pela quantidade de calor transferido entre sistemas que mantêm certo gradiente de temperatura, separados por diferentes materiais com as mesmas dimensões.
} 
C.4 - O calor tende a produzir o equilíbrio térmico entre os sistemas.

C.5 - A temperatura pode ser entendida como um índice que revela o sentido do fluxo de calor.

C.6 - O calor tende a aumentar a entropia do sistema, sendo, portanto, um processo irreversível.

C.7 - A variação de temperatura produzida por um dado fluxo de calor depende de características próprias do sistema, como a massa e o tipo de material de que esse sistema é formado.

C.8 - A energia se conserva em todas as transformações possíveis em um sistema isolado.

C.9 - Há uma equivalência entre calor e trabalho, posto que ambos os conceitos se referem a processos de transferência de energia.

C.10 - A entropia de um sistema está relacionada com o nível de "desordem" desse sistema e seu aumento é irreversível.

C.11 - Para um sistema qualquer, a energia interna representa a soma das energias cinética (associada à movimentação) e potencial (associada às interações) das partículas.

\section{Análise dos dados da pesquisa}

Para cada aluno acompanhado, foi construída uma tabela com as características mais marcantes dos modelos de partida, analisados a partir das respostas dadas no pré-teste, dos modelos explicativos construídos a partir das atividades propostas na seqüência de ensino e dos modelos caracterizados por meio das entrevistas clínicas. A análise dos modelos explicativos dos estudantes teve como base a procura pelos conceitos-em-ação e teoremas-em-ação utilizados pelos estudantes na resolução de tarefas relacionadas com a Física Térmica.

É importante notar que não foram incluídos nessa investigação os conceitos de energia interna e entropia. Isso se deve ao fato de que tais conceitos, sobretudo o de entropia, foram tratados superficialmente na seqüência de ensino e ainda seriam trabalhados pelo professor após o término da pesquisa. Assim, julgamos não ser conveniente explorar esses conceitos.

O estabelecimento das trajetórias de aprendizagem dos estudantes levou em consideração a maneira como os modelos explicativos evoluíram ao longo de um extenso período de tempo em que se deu o desenvolvimento da seqüência de ensino. Os momentos de identificação de tais modelos explicativos forneceram elementos para que pudéssemos inferir as rotas de construção utilizadas por cada 
sujeito pesquisado.

Na construção das trajetórias de aprendizagem, indicamos os pontos que pudemos perceber serem mais significativos na composição de um todo conceitual para a Física Térmica. Nem sempre esse todo conceitual pode ser construído, sendo que vários estudantes utilizavam diversos modelos explicativos - às vezes conflitantes entre si - para enfrentar uma dada classe de situações. Nesses casos, os modelos explicativos eram mais locais, em função do problema apresentado. Para outros estudantes, observamos um grau maior de coerência no uso do modelo em diferentes fenômenos. Podemos dizer que esses estudantes interpretaram tais fenômenos e situações em um contexto científico e fizeram uso de elementos de seu perfil conceitual adequados aos contextos encontrados (MORTIMER, 2000). De qualquer modo, a construção de um sistema coerente para os fenômenos térmicos foi verificada em muitos estudantes, o que interpretamos como uma compreensão mais global da termodinâmica como campo conceitual.

A tabela construída para cada estudante mostra os conceitos-em-ação e os teoremas-em-ação que puderam ser inferidos a partir da análise de todos os documentos obtidos ao longo da aplicação da seqüência de ensino e na realização das entrevistas. É importante salientar o caráter profundamente contextualizado dos conceitos e dos teoremas em ação, o que significa dizer que as respostas dos estudantes são enunciadas para uma dada situação escolhida dentre diversas outras e que, de certa forma, conduziram à utilização de alguns esquemas em detrimento de outros. Portanto, a indicação dos conceitos e teoremas em ação não pode ser tomada como algo absoluto e sim ser interpretada mediante a análise do contexto das situações que utilizamos nessa pesquisa.

A seguir, apresentaremos uma síntese das trajetórias de aprendizagem dos estudantes acompanhados. Optamos por apresentar, nesse artigo, apenas as comparações entre os traços mais marcantes de cada um dos estudantes. A caracterização de cada trajetória e dos estilos de aprendizagem dos estudantes foi feita em Carvalho (2005).

No quadro que será apresentado a seguir, mostramos uma síntese dos principais modelos que foram construídos pelos estudantes ao longo da aplicação da seqüência de ensino. Nele, procuramos enfatizar as características mais marcantes das elaborações dos estudantes que conseguimos identificar pela análise das respostas ao Pré-Teste (modelos de partida), aos Testes 1 (modelos explicativos 1) e 2 (modelos explicativos 2) e à Entrevista (modelos explicativos 3). Além disso, acrescentamos alguns modelos explicitados pelos estudantes nas atividades realizadas da seqüência de ensino. 
Para a construção da tabela, o item:

"(1)" refere-se ao conceito de calor;

“(2)" está relacionado com a temperatura;

“(3)” faz menção ao equilíbrio térmico;

“(4)" apresenta alguns modelos bastante peculiares.

\section{Modelos de Partida}

(1) Grande diversidade para o conceito de calor, que podia ser enunciado como (a) algo quente (Ana Paula, Cleiton e Flávia); (b) algo contido nos corpos (Eduardo e Samuel); entidade oposta ao frio (Carla) ou energia liberada (Lara).

(2) Pouca diversidade entre os estudantes para o conceito de temperatura, que podia ser enunciado como (a) quantidade de calor ou de energia dos corpos (Ana Paula, Carla, Cleiton, Eduardo, Flávia e Samuel) ou relacionado a sensações térmicas (Lara);

(3) O equilíbrio térmico não era reconhecido por todos como uma tendência de um sistema que interage termicamente.

(4) $\mathrm{Na}$ análise das respostas escritas pelo grupo na Leitura 01 da seqüência de ensino, percebemos um modelo que interpreta a dilatação térmica como o efeito da repulsão entre as partículas do corpo que foi aquecido. Em geral, os modelos explicativos dos sujeitos ainda carecem de maior consistência conceitual.

\section{Modelos Explicativos I}

(1) Houve uma menor diversidade de enunciados para o calor. Flávia continua afirmando que o calor é algo quente; Ana Paula apresenta uma mudança em seu conceito de calor, afirmando que é algo contido nos corpos. Os demais estudantes, em maior (Cleiton) ou menor (Lara e Samuel) escala, iniciam uma atribuição processual para o calor.

(2) Aumentou a diversidade nos conceitos de temperatura apresentados. As estudantes Lara e Ana Paula não superaram suas concepções iniciais, enquanto que os demais conseguiram algum tipo de evolução nesse conceito. Para Carla, Lara e Samuel, a temperatura pode ser alterada pelo movimento. Cleiton, Eduardo e Flávia fizeram menção ao modelo cinético para enunciar a temperatura, sendo que os dois primeiros, de forma correta e a última, de forma muito vaga.

(3) Somente Cleiton e Eduardo conseguiram apresentar formulações corretas para o equilíbrio térmico.

(4) Um modelo sobre a intensidade do calor foi utilizado pelos estudantes para a diferenciação entre isolantes e condutores térmicos. De acordo com esse modelo, os isolantes perdem calor (por isso não queimam) e os condutores absorvem calor (por isso queimam).

\section{Modelos Explicativos II}

(1) Este foi o ponto em que houve grande convergência entre os conceitos de calor utilizados pelos estudantes. Em geral, eles fizeram alguma menção à troca de energia, sendo que Flávia e Carla afirmavam que era um fluxo do que tem mais para o que tem menos calor, Ana Paula, Eduardo e Samuel simplesmente indicavam o sentido da troca de calor e Cleiton e Lara procuravam indicar o caráter processual do calor e seu sentido único.

(2) Ana Paula, Cleiton, Eduardo e Samuel revelaram um conceito de temperatura associado 
ao modelo cinético, sendo que Cleiton e Eduardo o fizeram com maior propriedade do que a primeira. Flávia e Lara relacionaram a temperatura com a energia de um corpo e não foi possível verificar o conceito de temperatura utilizado por Carla.

(3) Somente Ana Paula, Eduardo e Flávia não revelaram formulações para o equilíbrio térmico.

(4) O modelo utilizado por Samuel para a explicação do aquecimento por agitação, que afirma que a colisão entre as partículas "gera calor" continua a ser utilizado pelo estudante. Pela percepção de seu estilo de aprendizagem, podemos inferir que essa foi uma regra de ação que o estudante credita grande valor como auxílio na resolução de problemas. O modelo apresentado na primeira coluna voltou a ser utilizado pelos estudantes. Além disso, percebemos uma forte tendência, por parte dos alunos, a relacionar o aquecimento com a "agitação das partículas". A partir desse modelo, Carla e Samuel afirmam que a colisão entre as partículas "gera calor", transferindo propriedades macroscópicas para as partículas, enquanto Lara indica que as partículas podem aumentar a superfície de contato e produzir variações mais intensas de temperatura.

\section{Modelos Explicativos III}

(1) Também tivemos uma maior convergência em relação aos conceitos de calor utilizados pelos estudantes. Em geral eles reconheceram o sentido único para o calor nas situações apresentadas. Portanto, os estudantes parecem ter evoluído na utilização do conceito de calor em relação aos modelos de partida. Samuel utilizou um conceito de calor menos abrangente do que aquele revelado na verificação anterior, referindo-se a uma certa substancialização do calor.

(2) Cleiton, Eduardo, Lara e Samuel relacionaram, de alguma forma, a temperatura com a energia de um corpo, sendo que os três primeiros o fizeram com relação ao modelo cinéticomolecular. Ana Paula regrediu, ao conceito apresentado na primeira verificação e Carla não explicitou o conceito de temperatura.

(3) Carla, Cleiton, Eduardo e Samuel explicitaram a tendência ao equilíbrio térmico. Lara também se referiu ao equilíbrio térmico não como uma igualdade de temperatura, mas como uma igualdade nos fluxos de calor. Os demais estudantes não revelaram a noção de equilíbrio térmico.

(4) De uma forma geral, os estudantes revelaram conhecer que a intensidade do calor depende do material. Com relação a esse fato, Carla e Eduardo utilizaram um modelo que afirma serem os condutores capazes de variar mais intensamente a temperatura por transmitirem calor mais rapidamente, ao passo que os isolantes conduzem calor mais lentamente e, portanto, permanecem quentes por mais tempo.

\section{Considerações finais}

Vergnaud utiliza a sua teoria dos campos conceituais para a investigação das estruturas multiplicativas. Essa teoria não foi concebida no âmbito da Física, sendo esta uma aplicação que fizemos dos pontos que julgamos ser pertinentes da teoria de Vergnaud para a pesquisa em ensino de Física. 
Acreditamos que um dos pontos mais fortes da Teoria dos Campos Conceituais seja a preocupação que Vergnaud tem com o sujeito-em-situação. É essa característica que faz sua teoria ser muito útil no planejamento e na análise de situações de ensino em ciências naturais, uma vez que temos uma grande necessidade de acompanhar os alunos enquanto aprendem, procurando, nos conceitos e teoremas em ação, a evolução temporal de seu conhecimento.

Além disso, pelo fato de ser uma teoria complexa em que diversos conceitos devem ser considerados para que o sujeito possa dar conta de certa situação, a teoria dos campos conceituais permite ao professor pensar seu objeto de ensino de forma mais global. Os conceitos estudados, o nível de profundidade das abordagens e as avaliações das aprendizagens podem ser planejados a partir da seleção das situações que deverão ser enfrentadas pelos estudantes, ao longo de um determinado período de tempo.

Portanto, a teoria dos campos conceituais se apresenta como referencial teórico promissor para pesquisas em que se quer enfocar o sujeito em ato, envolvido em tarefas de ensino e aprendizagem. Do mesmo modo, essa teoria se apresenta como ferramenta poderosa na construção de planejamentos didáticos por parte dos professores, pois os auxilia no desenho de situações de ensino, na seleção dos conceitos e teoremas-chave e suas relações, assim como na análise da evolução temporal dos modelos explicativos dos sujeitos a partir da verificação dos conceitos e teoremas em ação utilizados.

\section{Agradecimentos}

Agradecemos os pareceres anônimos dos árbitros do CBEF, pelos comentários críticos e sugestões. Agradecemos, ainda, a leitura e comentários enviados por G. Vergnaud em correspondência pessoal com o primeiro autor deste trabalho.

\section{Referências}

AGUIAR JR., O. Modelo de ensino para mudanças cognitivas: um instrumento para o planejamento do ensino e a avaliação da aprendizagem em ciências. 2001. Tese (Doutorado) - Faculdade de Educação, UFMG, Belo Horizonte.

AGUIAR JR., O. ; FILOCRE, J. Modelos de ensino para mudanças cognitivas: fundamentação e diretrizes de pesquisa. Ensaio Pesquisa Em Educação Em Ciências, Belo Horizonte, v. 1, n. 1, p. 47-67, 1999. 
BITTAR, M. A teoria dos campos conceituais e o ensino de vetores no ensino secundário francês. Disponível em:

$<$ http://www.anped.org.br/25/excedentes25/marilenabittart19.rtf $>$ Acesso em: 27 jul. 2004.

CARVALHO JR., G. Trajetória de aprendizagem de estudantes de ensino médio: produção de significados em um curso introdutório de Física Térmica. 2005. Dissertação (Mestrado) - Faculdade de Educação, UFMG, Belo Horizonte.

CARVALHO JR., G. ; AGUIAR JR., O. Ensino de Física Térmica: uma abordagem do modelo de partículas. In: GARCIA, N. M. D. (Org.). SIMPÓSIO NACIONAL DE ENSINO DE FÍSICA, XV, 2003, Curitiba. Atas do XV Simpósio Nacional de Ensino de Física. Curitiba : CEFET-PR, 2003. p. 745 a 755. 1 CDROM. 2003.

CLEMENT, J. Model based learning as a key research area for science education. International Journal of Science Education, v. 22, n. 9, p. 1041-1053, 2000.

HESTENES, D. Modeling methodology for physics teachers. In: Proceedings of the International Conference on Undergraduate Physics Education, College Park, August 1996.

KAPER, W. H.; GOEDHART, M. F. "Forms of Energy", an intermediary language on the road to thermodynamics? Part I. International Journal of Science Education, v. 24, n. 1, p. 81-95, 2002.

KOLB, D. A. Experiential Learning: Experience as the source of learning and development. New Jersey: Prentice Hall, 1984.

MOREIRA, M. A.; AXT, R. Tópicos em ensino de Ciências. Porto Alegre: Sagra. 1991.

MOREIRA, M. A. A teoria dos campos conceituais de Vergnaud, o ensino de ciências e a pesquisa nesta área. Investigações em Ensino de Ciências, v. 7, n. 1, 2002. Disponível em: $<$ http://www.if.ufrgs.br/public/ensino/revista.htm>

MORTIMER, E. F. Linguagem e formação de conceitos no ensino de ciências. 1. ed. Belo Horizonte: Editora UFMG, 2000. v. 1. 
PIAGET, J. The equilibration of cognitive structures. Chicago: The University of Chicago Press, 1985.

SOUSA, C. M. S. G.; FÁVERO, M. H. Análise de uma situação de resolução de problemas de Física, em situação de interlocução entre um especialista e um novato, à luz da teoria dos campos conceituais de Vergnaud. Investigações em Ensino de Ciências, v. 7, n. 1, 2002. Disponível em:

$<$ http://www.if.ufrgs.br/public/ensino/revista.htm>

VERGNAUD, G. La théorie des champs conceptuels. Recherches en Didactique des Mathématiques, v. 10, n. 23, p. 133-170, 1990.

VERGNAUD, G. et al. Epistemology and psychology of mathematics education. In : NESHER, P. ; KILPATRICK, J. (Eds.) Mathematics and cognition: A research synthesis by International Group for the Psychology of Mathematics Education. Cambridge: Cambridge University Press, 1990.

VERGNAUD, G. Teoria dos campos conceituais. In: NASSER, L. (Ed.). SEMINÁRIO INTERNACIONAL DE EDUCAÇÃO MATEMÁTICA, 1, 1993, Rio de Janeiro. Anais do Semiário Internacional de Educação Matemática. p. 1-26.

VERGNAUD, G. A comprehensive theory of representation for Mathematics Education. Journal of Mathematical Behavior, v. 2, n. 17, p. 167-181, 1998.

VOSNIADOU, S. Capturing and modeling the process of conceptual change. Learning and Instruction, v. 4, p. 45-69, 1994. 